\title{
Antibody degradation in tobacco plants: a predominantly apoplastic process
}

\author{
Verena K Hehle, Matthew J Paul, Pascal M Drake, Julian KC Ma and Craig J van Dolleweerd
}

\begin{abstract}
Background: Interest in using plants for production of recombinant proteins such as monoclonal antibodies is growing, but proteolytic degradation, leading to a loss of functionality and complications in downstream purification, is still a serious problem.

Results: In this study, we investigated the dynamics of the assembly and breakdown of a human $\lg G_{1} \kappa$ antibody expressed in plants. Initial studies in a human IgG transgenic plant line suggested that lgG fragments were present prior to extraction. Indeed, when the proteolytic activity of non-transgenic Nicotiana tabacum leaf extracts was tested against a human IgG1 substrate, little activity was detectable in extraction buffers with $\mathrm{pH}>5$. Significant degradation was only observed when the plant extract was buffered below $\mathrm{pH} \mathrm{5,} \mathrm{but} \mathrm{this} \mathrm{proteolysis} \mathrm{could} \mathrm{be}$ abrogated by addition of protease inhibitors. Pulse-chase analysis of IgG MAb transgenic plants also demonstrated that IgG assembly intermediates are present intracellularly and are not secreted, and indicates that the majority of proteolytic degradation occurs following secretion into the apoplastic space.

Conclusions: The results provide evidence that proteolytic fragments derived from antibodies of the IgG subtype expressed in tobacco plants do not accumulate within the cell, and are instead likely to occur in the apoplastic space. Furthermore, any proteolytic activity due to the release of proteases from subcellular compartments during tissue disruption and extraction is not a major consideration under most commonly used extraction conditions.
\end{abstract}

\section{Background}

Plants are being developed as a manufacturing platform for a range of pharmaceutical proteins such as vaccines, hormones and antibodies. They are attractive for a number of reasons, including low production costs, the ability to assemble and modify multimeric proteins such as monoclonal antibodies (MAbs) and the ease of scalability. However, heterologous (plant-expressed) proteins often face significant yield losses due to proteolytic breakdown, which has widely been thought to be related to tissue homogenisation and protein extraction. There are many reports in the literature of degradation patterns manifesting as small fragments in gels and immunoblotting analyses [1-3]. Depending on the primary sequence of the heterologous protein, the number of susceptible sites and their accessibility to plant specific proteases, plant-expressed proteins may undergo complete proteolysis or partial trimming [4]. Antibodies are

\footnotetext{
* Correspondence: cvandoll@sgul.ac.uk

Molecular Immunology Unit, Division of Clinical Sciences, St George's, University of London, Cranmer Terrace, London SW17 ORE, UK
}

often subject to a significant degree of breakdown with between two to five major species (between $M_{r} 40 \mathrm{~K}$ and $M_{r} 160 K$ ) being reported under non-reducing conditions for different antibodies expressed in Nicotiana tabacum leaves [1-3,5-7]. As well as affecting the final yield of target proteins, degradation results in a heterogeneous mixture of recombinant proteins which may alter overall biological activity as well as complicating purification processes [8].

Plants produce proteases for a variety of reasons. Proteases are involved in classical biological processes such as plant development, disease resistance, and nutrient remobilisation for reproductive processes $[9,10]$. In addition, the timing and levels of protease expression can be viewed as markers for the senescence state of plants [11]. Over 800 proteases are encoded within the genome of Arabidopsis [10] and expressed in various tissues and organelles. Proteases are abundant in various subcellular compartments, including the vacuole [11] and the apoplast [10], the default destination for antibodies targeted to the secretory pathway $[12,13]$. 
It is widely believed that ex vivo degradation of the antibody occurs during the extraction process, as a result of proteases released during tissue and cell disruption $[14,15]$ and several strategies have been used to minimise this effect [15-17]. Most commonly, protease inhibitors are added to extraction buffers but these are expensive and therefore not economically viable for extraction at large scale. Other methods to prevent degradation of recombinant proteins have been proposed. Attempts to identify and knock out major protease families have met with limited success [10]. Alternative approaches include confining expression of proteins to selected cell compartments [18-20], targeting transgene expression to tissues with low metabolic turnover [21,22], co-expression of a specific recombinant protease inhibitor $[15,23]$, or by fusion to stabilising protein domains [24]. These are complicated by the fact that targeted proteases are often important for plant development, the broad spectrum of potential protease targets and compromises resulting from alternative in planta targeting strategies.
The objective of this study was to determine whether antibody degradation in transgenic plants is predominantly an intracellular or extracellular process and to identify whether processes involved in tissue disruption and protein extraction are indeed major contributors to proteolytic degradation of antibodies.

\section{Results}

The proteolytic degradation pattern of recombinant MAb 2G12 extracted from $N$. tabacum is not significantly affected by protease inhibition

Leaf samples from transgenic $N$. tabacum plants expressing the human $\operatorname{IgG}_{1} \kappa$ MAb 2 G12 were extracted in PBS ( $\mathrm{pH} 7.4$ ) in the presence or absence of a cocktail of protease inhibitors (Roche Protease Inhibitor Cocktail supplemented with pepstatin A). Analysis was by western blotting under non-reducing conditions (Figure 1), using $\operatorname{IgG}_{1}$ heavy chain-specific antiserum (Panel A) or light chain-specific antiserum (Panel B) for detection. A human $\operatorname{IgG}_{1} \kappa$ MAb, used as a positive control (PC), demonstrates a predominant band at $M_{r} 150 \mathrm{~K}$

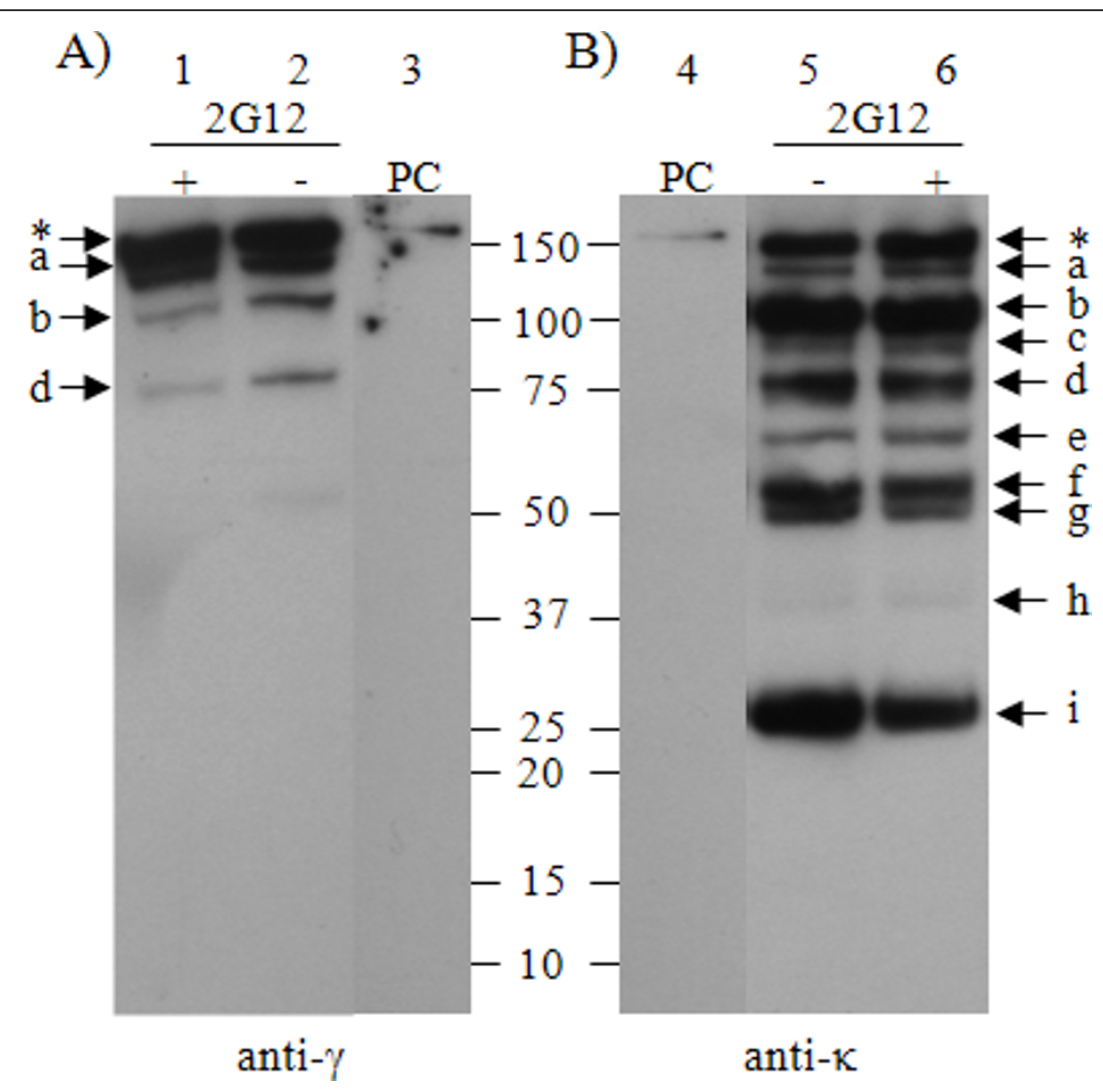

Figure 1 Western blot analysis of transgenic $\mathbf{N}$. tabacum plants expressing MAb 2G12. Leaf discs from 2G12-expressing plants were extracted in either PBS (-) or PBS supplemented with protease inhibitor cocktail (+) and incubated at room temperature for 24 hours. Proteins were separated by 4-15\% SDS-PAGE under non-reducing conditions. The proteins were blotted to nitrocellulose membranes and probed with either anti-human IgG Fc-specific antiserum (Panel A) or anti-human $\kappa$ antiserum (Panel B). The positive control (PC) consists of the human $\operatorname{lgG} 1 \kappa(1 \mathrm{ng} / \mathrm{lane})$. The asterisk indicates the fully assembled 2G12 antibody; lower case letters (a to i) indicate antibody fragments. 
(indicated with an asterisk) corresponding to fully assembled antibody. In the plant samples, the corresponding major band was always detected. A band at a slightly lower molecular weight $\left(\mathrm{M}_{\mathrm{r}} \approx 140 \mathrm{~K}\right)$ was also detected in both anti-gamma and anti-kappa blots (Figure 1, Panels A and B; labelled a). Together with band $\mathrm{b}$ $\left(M_{r} 100 K\right)$ and band $d\left(M_{r} 75 K\right)$, these were the only major, lower molecular weight species detectable in the anti-gamma blot. In comparison, at least nine bands of lower molecular weight were observed in the anti-kappa blot (Figure 1, Panel B) labelled (a-i). Since some of these bands have molecular weights greater than $M_{r}$ $25 \mathrm{~K}$ (the expected size for free light chain), the presence of heavy chain fragments is implied, even though no corresponding fragments are observed in the antigamma blot. This was a consistent finding and was also observed when several other human gamma chain-specific antisera were used. Inclusion of a cocktail of protease inhibitors in the extraction buffer did not significantly affect the intensity of the $M_{r} 150 \mathrm{~K}$ band, or the pattern of smaller bands on the western blots (compare lane 1 with lane 2 and lane 5 with lane 6).
Protein A/G affinity chromatography was used to purify the antibody mixture (i.e., both fully assembled and lower molecular weight fragments) from 2 G12 extracts. These purified proteins were analysed by Coomassie staining of SDS-acrylamide gels under reducing conditions (Figure 2, Panel A). This figure shows that the fully assembled 2G12 antibody and the co-purified lower molecular weight species observed in Figure 1, Panels A and B resolve into two major bands, one of apparent molecular weight $\mathrm{M}_{\mathrm{r}} \approx 55 \mathrm{~K}$ and the other with $\mathrm{M}_{\mathrm{r}} \approx 25 \mathrm{~K}$ (labelled $\mathrm{H}$ and $\mathrm{L}$, respectively). The relative molecular weights of these two species, particularly when compared with the free heavy and light chains in the reduced positive control (PC) provide evidence that these 2 G12 plant-derived bands are free heavy and free light chains. This is supported by their immunoreactivity with human Fc fragment-specific antiserum (Figure 2, H in Panel B) or human kappa chain-specific antiserum (Figure 2, L in Panel C). In addition, five breakdown fragments (labelled a, b, c, d and e) are also observed. Two of these fragments (a and d) appear to correspond to bands seen in the

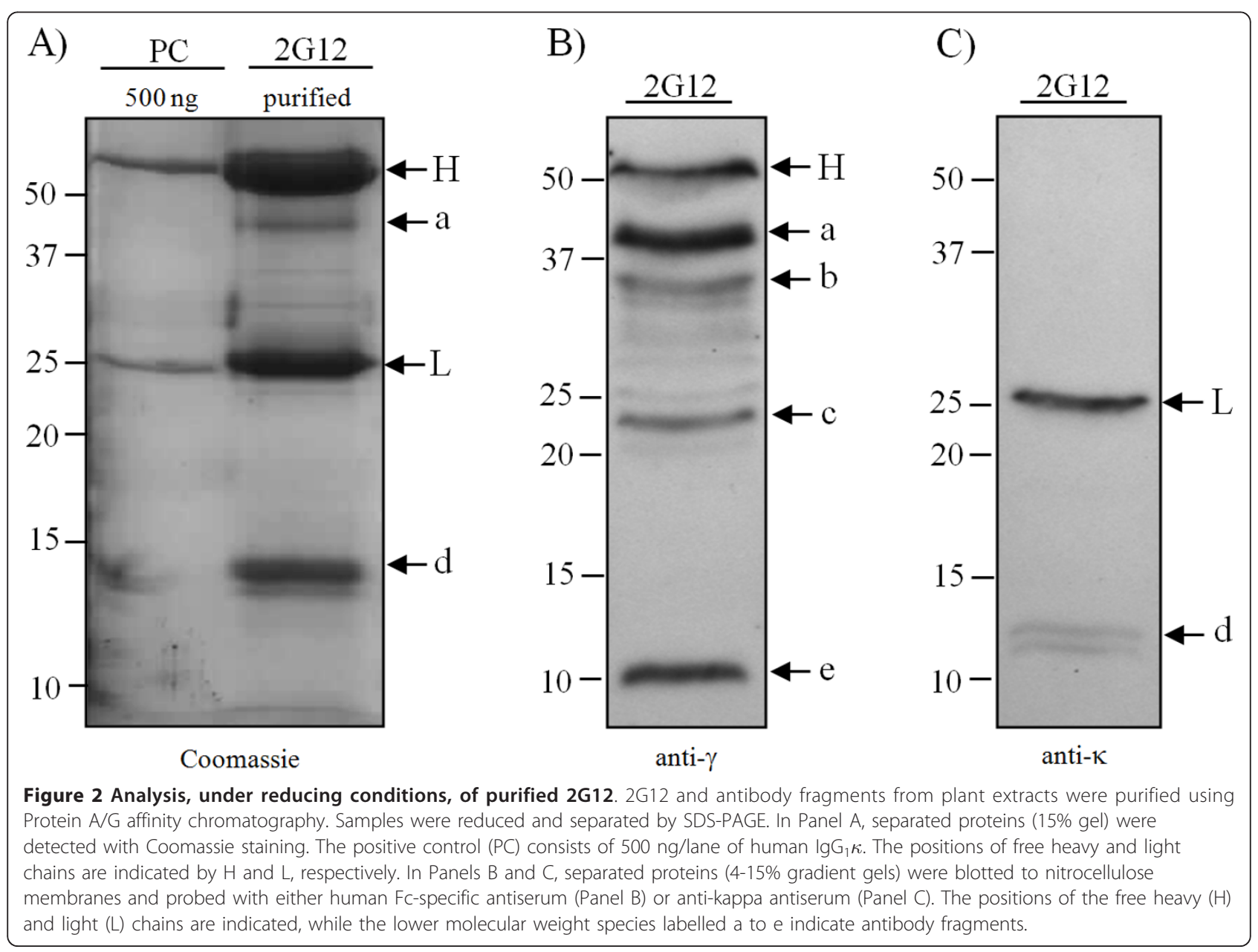


Coomassie-stained gel. Fragments $\mathrm{b}\left(\mathrm{M}_{\mathrm{r}} \approx 35 \mathrm{~K}\right), \mathrm{c}\left(\mathrm{M}_{\mathrm{r}}\right.$ $\approx 23 \mathrm{~K})$ and $\mathrm{e}\left(\mathrm{M}_{\mathrm{r}} \approx 11 \mathrm{~K}\right)$ could only be detected with the human Fc-specific antiserum (Panel B). Band d $\left(\mathrm{M}_{\mathrm{r}} \approx 12 \mathrm{~K}\right)$ was only reactive with the kappa chainspecific antiserum (Panel $\mathrm{C}$ ).

\section{N. tabacum leaf extracts at neutral pH exhibit little proteolytic activity against IgG}

The presence of the majority of immunoglobulin fragments in plant extracts prepared with protease inhibitor cocktail suggested that proteolytic degradation might occur predominantly in planta prior to extraction. In order to investigate the influence of proteases released during the extraction process, we used Nicotiana tabacum leaf extracts from non-transgenic plants, prepared in either PBS (pH 7.4) or PBS supplemented with a protease inhibitor cocktail, to which a standard amount of a human $\operatorname{IgG}_{1} \kappa$ MAb was added. Samples were incubated for either 15 mins, 2 hrs or 24 hrs at room temperature and analysed by western blotting (Figure 3), using an anti-gamma chain antiserum (Panel A) or anti-kappa chain antiserum (Panel B).

The commercial MAb preparation consists of a predominant single band (labelled with an asterisk) at the expected $M_{r}$ of $\approx 180 \mathrm{~K}$ (Lane $\mathrm{PC}$ ). The smaller fragments (bands labelled a and b) were also evident in both anti-heavy and anti-light chain blots.

This pattern of bands was not significantly affected by incubation with the tobacco extract for up to $24 \mathrm{hrs}$. The intensities of these bands did not vary over time. Moreover, the addition of the cocktail of protease inhibitors had no significant effect at any of the time points. A faint band $\left(M_{r} \approx 120 \mathrm{~K}\right.$, labelled $\left.\mathrm{c}\right)$ was observed on some blots due to specific blotting conditions. This band is unlikely to be the result of proteolytic degradation in the plant extract as it is also present in the positive control lanes in Figure 4 Panels A-C.

\section{IgG proteolysis by tobacco plant extracts is activated at acidic $\mathrm{pH}$}

In the next experiment, the influence of extraction buffer $\mathrm{pH}$ on the proteolytic activity of $N$. tabacum leaf extracts was investigated. Leaf tissue was extracted in buffers at different $\mathrm{pH}$ and incubated at room temperature with exogenous human IgG. Samples were taken after 15 mins, 2 hrs or 24 hrs and analysed by SDSPAGE and western blotting using an anti-gamma chain antiserum (Figure 4, Panels A-C). The results showed that at $\mathrm{pH}>6$, there was no significant change in the intensity of the intact IgG (labelled with an asterisk). The smaller bands $\mathrm{a}, \mathrm{b}$ and $\mathrm{c}$ (all present this time in the control sample) did not alter in intensity with decreasing $\mathrm{pH}$. This is true for all the time points investigated (Figure 4, Panels A-C). At pH 5, the intensity of band a increased at all three time points. When the $\mathrm{pH}$ was reduced further to 4.2 or 3 , a dramatic loss of immunoreactive material occurred, even at the 15 mins time point.

In order to verify whether $\mathrm{pHs}<5$ might be responsible for the activation of proteases present in $N$. tabacum leaf extracts, we compared IgG samples that were incubated with plant extracts at $\mathrm{pH} 7.4, \mathrm{pH} 4.2$ or $\mathrm{pH} 3$, in the presence or absence of a protease inhibitor cocktail. Samples were incubated for 24 hrs and analysed by western blotting using an anti-human Fc antiserum (Figure 4, Panel D) or anti-human light chain antiserum (Figure 4, Panel E). In the absence of protease inhibitors, no significant degradation was seen at $\mathrm{pH} 7.4$, but extensive antibody degradation was observed at $\mathrm{pH} 4.2$ and $\mathrm{pH} 3$, as before. However, addition of the protease inhibitor cocktail almost completely abrogated the antibody loss at low $\mathrm{pH}$.

As $\mathrm{pH}$ affected the proteolytic activity of tobacco leaf extracts on exogenous IgG, the effect of extraction buffer $\mathrm{pH}$ on MAb $2 \mathrm{G} 12$ expressed in transgenic plants was examined. Leaf discs were extracted in different $\mathrm{pH}$ buffers as before and incubated for 15 mins or $24 \mathrm{hrs}$ at room temperature. Samples were analysed by SDSPAGE and western blotting. Immunoreactive bands were detected with anti-kappa antiserum (Figure 5). Recombinant antibody extracted under these conditions was already extensively degraded, as previously observed in Figure 1, but between $\mathrm{pH} 5-8$, there was little difference between the analysed samples, either after 15 mins (Figure 5, Panel A) or 24 hrs incubation (Figure 5, Panel B). At $\mathrm{pH} 4.2$ and $\mathrm{pH} 3$, there was extensive degradation of the antibody. Interestingly, the loss of intact IgG is not associated with the appearance of new degradation bands or increased intensity of existing degradation products, rather it appears that there is complete loss of immunoreactivity of all bands.

\section{Analysis of MAb 2G12 fragments and secretion in transgenic plant cells}

Protoplasts prepared from MAb 2 G12 transgenic plants were pulse-labelled for 30 mins, and subsequently chased following the addition of cold amino acids over a period of 4 hours. During the chase, samples were taken at 0 hrs, 1 hour, 2 hrs and 4 hrs, immunoprecipitated and visualised by SDS-PAGE and auto-radiography to investigate secretion and degradation of MAb 2 G12 under nonreducing conditions (Figure 6, Panel A) and reducing conditions (Figure 6, Panel B). Intact MAb 2 G12 (indicated with an asterisk) was identified in the protoplasts at 0 hrs. The amount of intact MAb diminished with time inside the protoplasts, concomitant with a gradual increase in full length MAb in the medium. This indicates efficient secretion of MAb 2G12, as has been 


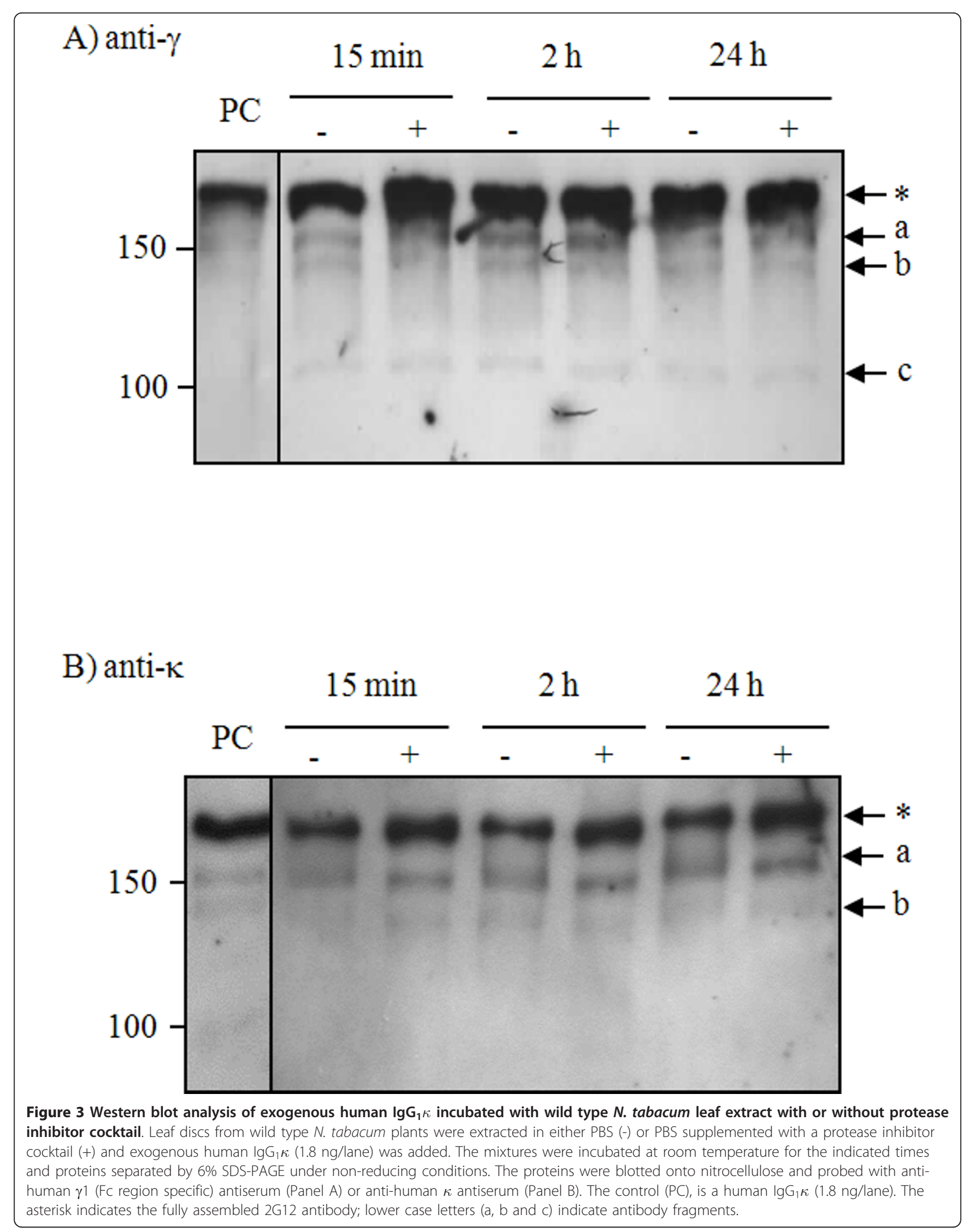




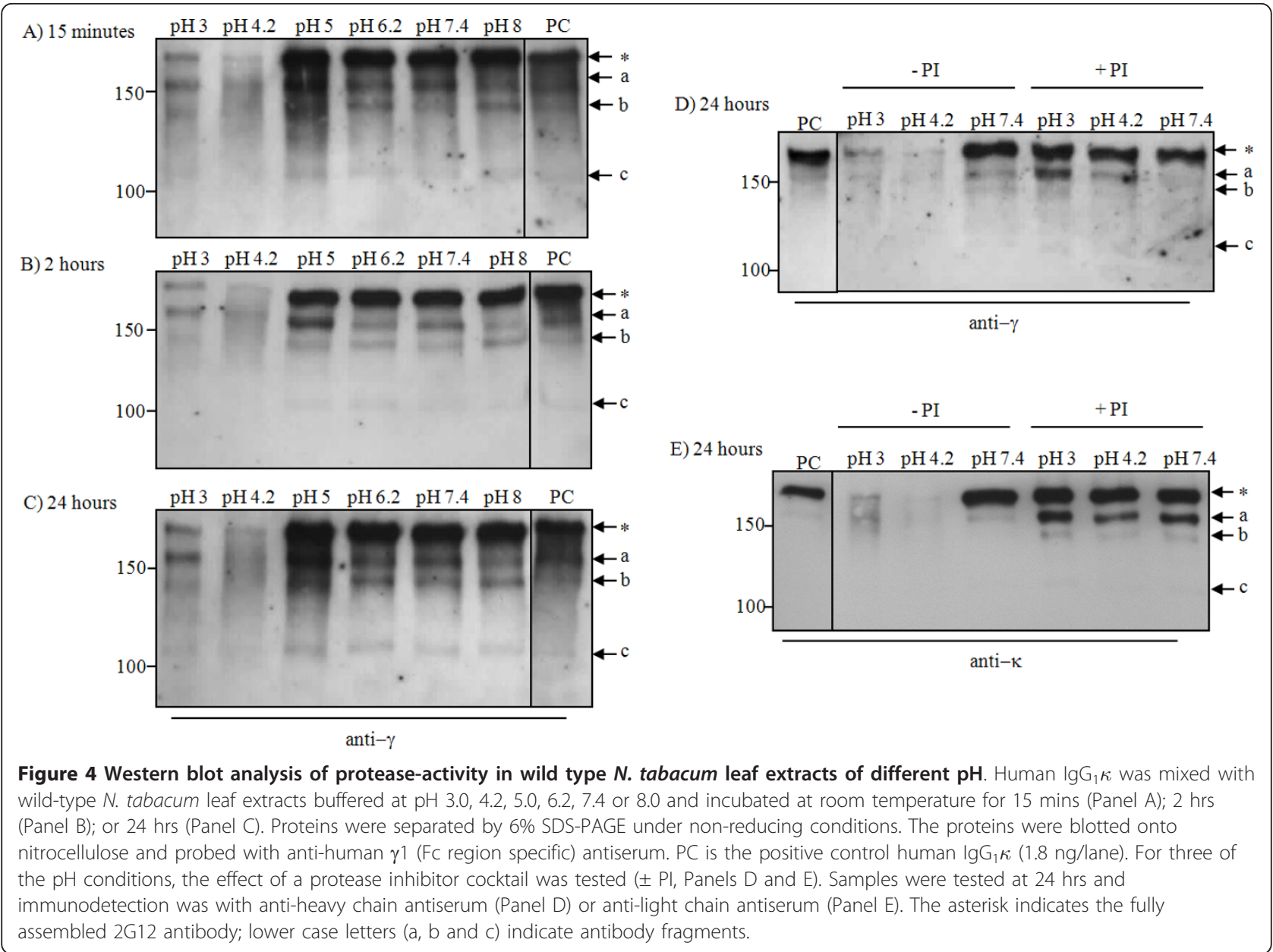

described previously for another MAb [25]. The characteristic pattern of smaller species (a, b, d, g, h and i) was observed in the cellular samples. Three of these bands (bands a, b and g) decreased in intensity over time, whereas others seemed to be stable within the cell (bands $d, h$ and i). The result suggests that fully assembled MAb 2 G12 is efficiently secreted from transgenic plant cells, while smaller immunoreactive species of MAb 2G12 are present intracellularly, remain in the cell and are not secreted, with the exception of band $d$ which was visible after 2 hrs chase in the medium. Under reducing conditions (Panel B) free heavy chain (indicated $\mathrm{H}, \mathrm{M}_{\mathrm{r}} \approx 55 \mathrm{~K}$ ) and free light chain (indicated $\mathrm{L}, \mathrm{M}_{\mathrm{r}} \approx 25 \mathrm{~K}$ ) were the only bands detected by radiolabelling.

To establish the pattern of antibody bands within the cells under steady state conditions, unlabelled protoplasts were prepared from leaf tissue of two month old transgenic plants expressing MAb 2G12 and analysed by SDSPAGE and western blotting under non-reducing (Panel C) and reducing conditions (Panel D). For each condition, these results were compared to the pattern obtained from a crude extract of the same leaf material. At steady state, free heavy or light chain were again the only bands detected under reducing conditions within the cells, whereas several additional fragments could be observed in the crude extract. The presence of bands that did not correspond to assembly intermediates was also apparent in the non-reduced crude sample (Panel C).

\section{Discussion}

Many recombinant MAbs extracted from transgenic plants demonstrate a characteristic and reproducible pattern of fragmentation. Such a pattern was observed in the MAb 2 G12 plants studied here. Despite findings which show that recombinant protein degradation occurs in vivo $[25,26]$, the possibility that degradation fragments are formed as a result of proteases that are activated during plant cell and tissue disruption cannot be excluded [14]. As a consequence, it is routine practice to include a range of protease inhibitors in extraction buffers. However, the efficacy of protease inhibitors has never been proven, furthermore they are frequently expensive and unlikely to be practical for commercial scale up. 


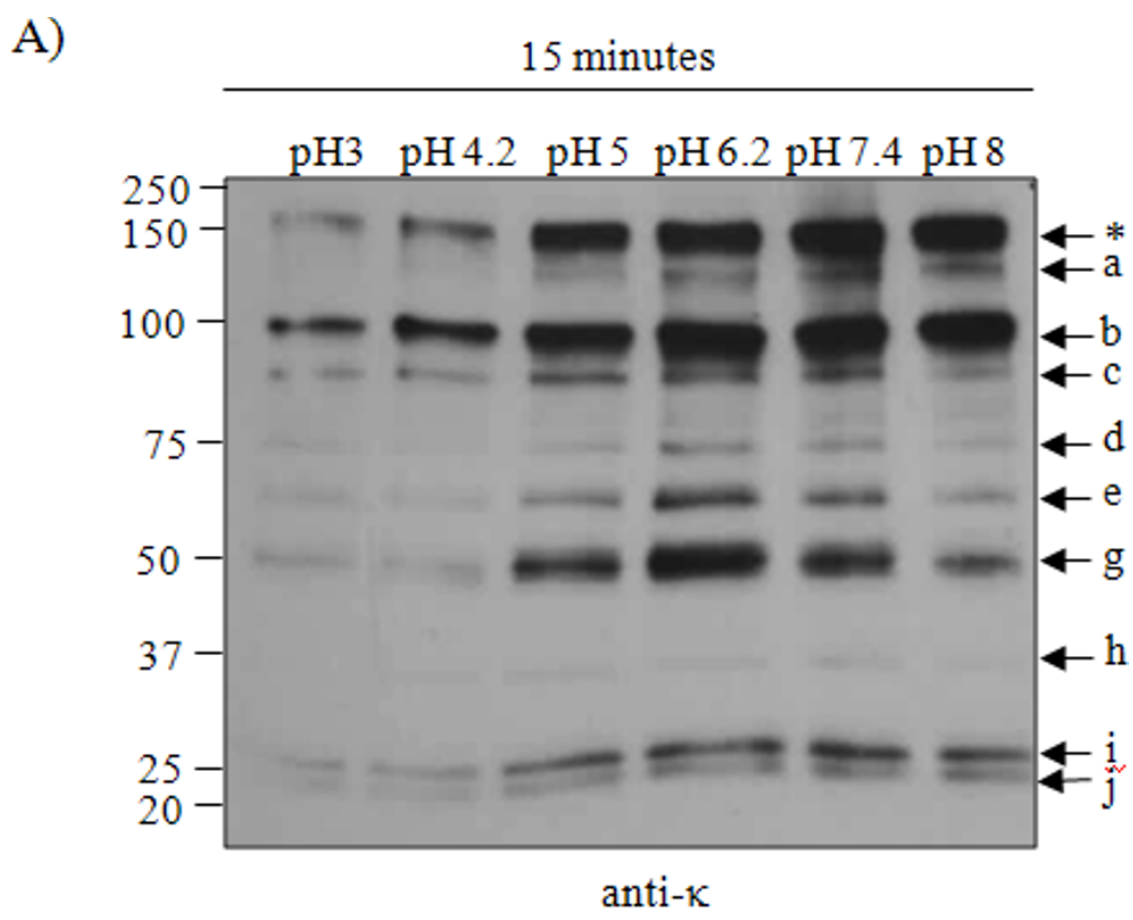

B) 24 hours

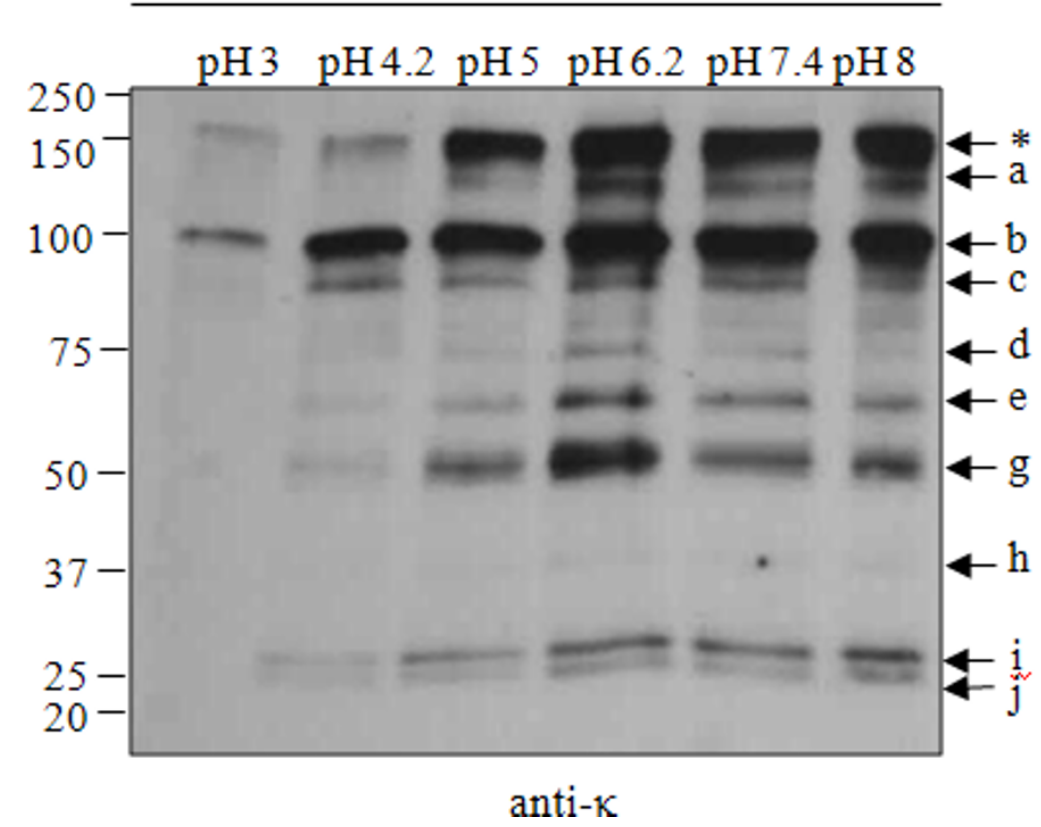

Figure 5 Western blot analysis of recombinant MAb $2 \mathrm{G} 12$ extracted from transgenic $\mathbf{N}$. tabacum in different pH-buffers. Leaf discs from MAb 2G12-expressing plants were extracted in solutions buffered to; $\mathrm{pH}$ 3.0, pH 4.2, $\mathrm{pH}$ 5.0, pH 6.2, pH 7.4, or pH 8.0. The mixtures were incubated at room temperature for 15 mins (Panel A) or 24 hrs (Panel B). Proteins were separated by SDS-PAGE under non-reducing conditions. Proteins were blotted onto nitrocellulose membranes and probed with anti-human $\kappa$ antiserum. The asterisk corresponds to the fully assembled 2G12 antibody, while the lower case letters (a to j) indicate antibody fragments. 


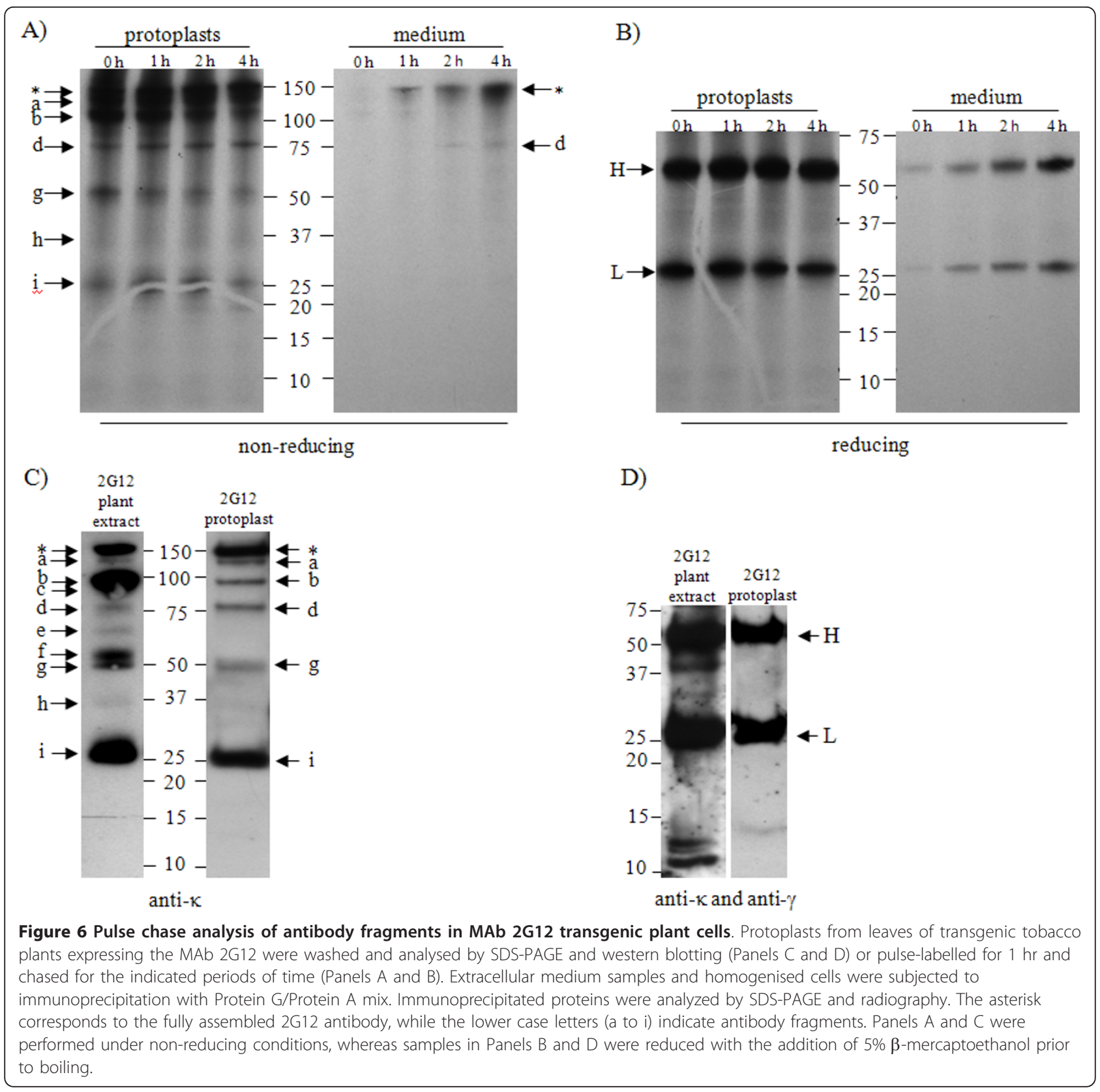

The identity of the IgG fragments has also not yet been determined. Whilst some may represent assembly intermediates of IgG (e.g., free heavy or light chains, H/ $\mathrm{L}$ heterodimers or $\mathrm{H} / \mathrm{H}$ homodimers), these cannot account for all of the fragments observed. Indeed, when analysed under reducing conditions (Figure 2), fragments with a lower molecular weight than the free heavy and free light chains were observed and these can only be due to degradation. Based on the data presented, tentative assignments have been made for each of the bands observed in Figure 1B. Species which correspond to bands present in the protoplast preparation
(Figure 6, Panel D) are likely to be assembly intermediates (bands a, b, d, g and i in both figures), as no other fragments were observed in protoplasts under reducing conditions. Band g shares a molecular weight $\left(M_{r} 50 K\right)$ with a species previously described as a degradation fragment (Fab-like fragment) [3,5,27]. This possibility cannot be excluded as the predicted mobility of both components of a reduced Fab-like fragment matches that of the light chain. Bands c, e, $\mathrm{f}$ and $\mathrm{h}$ in Figure 1B were present only in the plant tissue extract (Figure 6, Panel C), and are likely to originate in the apoplastic space as they were not affected by the addition of 
protease inhibitor (Figure 1, Panel B) and are not apparent in the protoplast preparation (Figure 6, Panel C).

The loss of plant-expressed antibodies due to proteolytic degradation ex planta and in planta is a major concern regarding stability, final yield of plant-expressed MAbs and validation of purification. Development of strategies to prevent proteolytic degradation of plantexpressed antibodies would therefore be a worthwhile consideration, so it is important to understand when and where this degradation occurs.

Non-transgenic $N$. tabacum leaf extracts have little or no anti-IgG proteolytic activity in the $\mathrm{pH}$ range commonly used for experimental extraction. In addition, the use of a broad acting cocktail of protease inhibitors at high concentration had little effect on the IgG fragment pattern for MAb 2G12. These findings suggest that degradation of MAb $2 \mathrm{G} 12$ is not related to the process of extraction, more likely, degradation occurs before extraction, and either along the secretory pathway, in the apoplastic space, or in subcellular storage compartments [28]. These observations support the findings of Hassan et al. [29] who showed little benefit from using protease inhibitors during the extraction of a murine $\operatorname{IgG}_{1} \kappa$ at neutral $\mathrm{pH}$ to prevent the loss of functional MAb. Endoproteases that can degrade monoclonal antibodies are undoubtedly released during the extraction process $[17,30,31]$, but significant proteolytic activity was only observed here at $\mathrm{pH}<5$ and in this instance, degradation could be countered by the protease inhibitor cocktail.

At low pH, degradation of IgG is characterised by a complete loss of MAb, rather than the appearance of new, smaller species. An explanation for this phenomenon could be that plant proteases active in acidic conditions (e.g. aspartic acid proteases) may show extensive activity on antibody Fc regions, degrading it to smaller peptides [32,33]. Kim et al. [34] suggested that under acidic conditions ( $\mathrm{pH}$ 3.9) a conformational change in the $\mathrm{Fc}$ region of an IgG takes place, which makes the antibody more accessible to proteases.

The organelles of the early secretory pathway are the sites of initial polypeptide folding and maturation. Given these roles, the luminal compartments of these organelles are not widely recognised as possessing broadspectrum proteolytic activity. The established paradigm for 'quality control' in the ER consists of prolonged association with ER-resident chaperones, N-glycan modification, retrotranslocation and complete degradation by the proteasome in the cytosol $[35,36]$. Alternative routes for luminal disposal of proteins that fail to mature have been mooted, either through trafficking in a complex with BiP to the vacuole [37] or via an ER subdomain rich in proteases [38]. It is important to remember that antibodies have not evolved in the context of the plant protease degradome, and they could therefore represent novel targets for plant proteases [14]. However, previous studies on transgenic tobacco tissue have shown that by blocking early transport events in the secretory pathway, and thereby causing an accumulation of antibody in an ER-Golgi super-compartment, the accumulation of intact mouse $\operatorname{IgG}_{1}$ MAb could in fact be markedly improved [2]. High levels of intact recombinant protein have been reported to accumulate in ER-derived compartments, such as protein bodies [39].

Here, we have shown that IgG-expressing protoplasts do not accumulate MAb proteolytic fragments when analysed at steady state. Furthermore, a discrete pulse of expression analysed over a 4-hour chase period revealed no species that did not correspond to the predicted mobility of an IgG assembly intermediate. Hence, it would appear unlikely that discrete intracellular proteolytic fragments are not detectable at steady state due to rapid clearance through further degradation. In similar pulse-chase experiments, Hadlington et al. describe the formation of fragments characteristic of vacuolar proteolysis when a hybrid murine MAb with both gamma and alpha constant regions was expressed in protoplasts [40]. These fragments were not observed in our experiments. Over the course of the chase, several smaller species are lost from the protoplasts apparently without fragmentation or secretion into the medium, which suggests that a significant proportion of IgG tetramers undergo a delayed assembly. The cause of this slow assembly is unclear, although it has been reported that an excess of light chain may be required for efficient release of heavy chain from the heat shock protein 70 (HSP70) family chaperone $\mathrm{BiP}$ [41], and no attempt was made here to optimise the stoichiometry of the components.

In contrast to the secretory pathway, the apoplast is a likely compartment for the formation and accumulation of the proteolytic fragments observed in these experiments. The $\mathrm{pH}$ of apoplastic fluid is between $\mathrm{pH}$ 5-6 [42]. The apoplastic space is regarded to be rich in acidic proteases $[6,7]$ and a number of candidate proteases have been identified. Secretion of six proteases into the leaf apoplastic space of different plant species (tomato, Arabidopsis, N. benthamiana), belonging to the cysteine protease (papain-like), aspartic protease (pepsin-like) and serine protease (subtilisin-like and carboxypeptidase-like) families has been reported [10]. Seventeen peptides corresponding to predicted plant aspartic, cysteine, and serine proteases were identified from zymography of intercellular fluid from $N$. tabacum [43]. A plasma membrane associated metalloproteinase has recently been reported in tobacco cells [44], and a member of the legumain Asn-specific cysteine endopeptidase family has also been described in the plant cell wall [45]. 


\section{Conclusions}

We conclude that the fragmentation pattern of heterologously expressed MAb in $N$. tabacum is not primarily due to proteolysis arising during extraction unless acidic extraction buffers are used. Instead, the fragmentation pattern observed when samples are subjected to SDSPAGE under reducing conditions appears to reflect in planta proteolysis, and this activity was restricted to the apoplast rather than the cells. If this is the case, it is unlikely that any extraction strategy that utilises exogenous measures to control proteolytic degradation will have a significant effect. Measures aimed at preventing degradation of IgG within the apoplastic space have the potential to increase yield and homogeneity of this important class of molecule and need to be explored further.

\section{Methods}

Plant material

Nicotiana tabacum (var. xanthi) plants (2-3 months old) were used. They were either wild-type (non-transgenic) or transgenic and homozygous for the $\gamma$ and $\kappa$ chains of the human $\mathrm{IgG}_{1} \kappa$ MAb 2 G12 (kindly provided by Thomas Rademacher and Eva Stöger). For each sample, a single leaf disc (average mass $=7.56 \mathrm{mg}$ ) was excised from a young leaf using the lid of a $1.5 \mathrm{ml}$ Eppendorf tube as a punch. Leaf discs were homogenised using a plastic pestle in a $1.5 \mathrm{ml}$ microcentrifuge tube and incubated with $300 \mu \mathrm{l}$ of the appropriate extraction buffer.

\section{Antibody stability in crude plant extracts}

A range of extraction buffers at different $\mathrm{pHs}$ were used for the extraction. These were phosphate buffered saline (PBS) at $\mathrm{pH} 7.4 ; 0.1 \mathrm{M}$ citric acid-phosphate buffer at $\mathrm{pH}$ 3.0, 4.2, 5.0, or 6.2, or $50 \mathrm{mM}$ Tris- $\mathrm{HCl}$ buffer at $\mathrm{pH}$ 8.0. In some cases, where indicated, the extraction buffer was supplemented with $7 x$ Complete ${ }^{\circledR}$ Protease Inhibitor Cocktail (Roche, UK) and $7 \mathrm{mg} / \mathrm{ml}$ pepstatin A (Sigma, UK).

Extracted samples were centrifuged for 5 mins at 17 $000 \times \mathrm{g}$ and the supernatant collected.

For experiments involving supplemented (exogenous) antibody, a human $\operatorname{IgG}_{1} \kappa$ MAb (The Binding Site, UK) was added to wild type plant extracts to a final concentration of $0.2 \mathrm{ng} / \mu \mathrm{l}$. Samples were incubated for 15 mins, 2 hrs or 24 hrs at room temperature, before being analysed by SDS polyacrylamide gel electrophoresis (SDS-PAGE) and western blotting.

\section{Protein purification}

Transgenic N. tabacum plants expressing 2G12 MAb were ground in PBS (pH 7.4). The homogenate was centrifuged for 30 mins at $15000 \times g, 10^{\circ} \mathrm{C}$, the supernatant filtered through No. 3 Whatman paper, the $\mathrm{pH}$ adjusted to 7.6 and incubated on ice for 30 mins. The sample was centrifuged again $\left(170000 \times \mathrm{g}, 30 \mathrm{mins}, 10^{\circ} \mathrm{C}\right)$ and the supernatant was filtered $(0.22 \mu \mathrm{m}$, Millipore $)$ and loaded onto a mixed Protein G-Sepharose (Sigma, P3296)/Protein A-Agarose (Sigma, P3476) column. The column was washed with PBS, antibody eluted with 100 $\mathrm{mM}$ glycine $(\mathrm{pH} 2.5)$ and the $\mathrm{pH}$ of the eluate neutralised with $1 \mathrm{M}$ Tris base ( $\mathrm{pH}$ unadjusted).

\section{SDS-PAGE and western blotting}

Protein samples were separated on either $15 \%$ polyacrylamide gels under reducing conditions, $6 \%$ polyacrylamide gels or $4-12 \%$ Bis-Tris gradient gels (Invitrogen) under non-reducing conditions. Aliquots $(60 \mu \mathrm{l})$ of the processed samples were boiled for 3 mins with $15 \mu \mathrm{l}$ of 5x SDS-PAGE sample buffer, (50\% (v/v) glycerol, $10 \%$ $(\mathrm{v} / \mathrm{v})$ sodium dodecylsulfate, $0.3125 \mathrm{M}$ Tris- $\mathrm{HCl}(\mathrm{pH}$ 6.8 ) and $0.125 \%(\mathrm{w} / \mathrm{v})$ bromophenol blue) for analysis under non-reducing conditions, or supplemented with $\beta$-mercaptoethanol to $5 \%(\mathrm{v} / \mathrm{v})$ for analysis under reducing conditions. As a control in the western blotting, a human IgG $\mathrm{I}_{1} \kappa \mathrm{MAb}$ (The Binding Site, UK) was loaded at either $1 \mathrm{ng} / \mathrm{lane}$ or $1.8 \mathrm{ng} / \mathrm{lane}$. Separated proteins were blotted onto nitrocellulose membranes using a semi-dry transfer device (BioRad). The membranes were incubated with $5 \%(\mathrm{w} / \mathrm{v})$ non-fat milk powder in TBS for at least 30 mins to block free protein binding sites. A polyclonal HRP-labelled goat anti-human IgG (Fc fragment) antiserum (Jackson ImmunoResearch, 109035-008) was used for detection of the heavy chain. Detection of the light chain was performed with an HRP-labelled anti-human kappa $(\kappa)$ reagent (Sigma, A7164). Blots were washed five times with PBS containing $0.2 \%(\mathrm{v} / \mathrm{v})$ Tween 20 and developed using the ECL Plus western blotting detection system (GE Healthcare).

For Coomassie staining, Protein A/G purified plant samples were separated on SDS-acrylamide gels under reducing conditions (5x SDS-PAGE sample buffer supplemented with $5 \%(\mathrm{v} / \mathrm{v}) 2$-mercaptoethanol) and incubated for $1 \mathrm{hr}$ with Coomassie InstantBlue (Expedeon). A human $\operatorname{IgG}_{1} \kappa$ MAb (The Binding Site, UK), used as a positive control (PC), was loaded at $500 \mathrm{ng} / \mathrm{lane}$.

\section{Preparation of protoplasts and in vivo labelling}

Leaves from 4-6 week old transgenic $N$. tabacum plants expressing MAb $2 \mathrm{G} 12$ were used for the preparation of protoplasts as described in Pedrazzini [46] and incubated for $16 \mathrm{hrs}$ in 4\% (w/v) Cellulase Onozuka R-10, 2\% (w/v) Macerozyme Onozuka R-10 (Apollo Scientific), in K3 medium (Gamborg's B5 basal medium with minimal organics, $3.78 \mathrm{~g} / \mathrm{L}$; supplemented with $750 \mathrm{mg} / \mathrm{L}$ $\mathrm{CaCl}_{2} \cdot 2 \mathrm{H}_{2} \mathrm{O} ; 250 \mathrm{mg} / \mathrm{L} \mathrm{NH}_{4} \mathrm{NO}_{3} ; 136.2 \mathrm{~g} / \mathrm{L}$ sucrose; 250 $\mathrm{mg} / \mathrm{L}$ xylose; $1 \mathrm{mg} / \mathrm{L}$ 6-benzylaminopurine; and $1 \mathrm{mg} / \mathrm{L}$ $\alpha$-naphthalene acetic acid, $\mathrm{pH} 5.5)$ at $25^{\circ} \mathrm{C}$ in the dark. Tissue disruption and recovery of viable protoplasts was 
in $\mathrm{K} 3$ medium. The radiolabelling period $(50 \mu \mathrm{Ci} / \mathrm{ml}$ Expre ${ }^{35} \mathrm{~S}^{35} \mathrm{~S}$ cell labeling mix $\left(73 \% \mathrm{~L}-\left[{ }^{35} \mathrm{~S}\right]\right.$ methionine and $22 \% \mathrm{~L}-\left[{ }^{35} \mathrm{~S}\right]$ cysteine; Perkin Elmer, Beaconsfield, UK) was for 30 mins and the chase was started with the addition of excess cold amino acids (time point $0 \mathrm{~h}$ ). Samples were taken at 0 hours, 1 hour, 2 hours and 4 hours after labelling and protoplast were precipitated by the addition of three volumes of W5 medium $(154 \mathrm{mM}$ $\mathrm{NaCl}, 5 \mathrm{mM} \mathrm{KCl}, 125 \mathrm{mM} \mathrm{CaCl}_{2} \cdot 2 \mathrm{H}_{2} \mathrm{O}$, and $5 \mathrm{mM}$ glucose). Samples were homogenized in homogenisation buffer (150 mM Tris-HCl, pH 7.5; $150 \mathrm{mM} \mathrm{NaCl} ; 1.5 \%$ $(\mathrm{v} / \mathrm{v})$ Triton X-100) or 2 volumes of the same buffer containing $0.25 \%(\mathrm{w} / \mathrm{v})$ gelatin, respectively; supplemented with one tablet of Complete Protease Inhibitor Cocktail (Roche) per $15 \mathrm{ml}$ ). Immunoprecipitation of labeled samples was performed as described in Pedrazzini [46] with a mix of Protein A-Agarose beads (Sigma) and Protein G-Sepharose beads (Sigma) in NET buffer (50 mM Tris-HCl, pH 7.5; 150 mM NaCl; 1 mM EDTA; $0.1 \%(\mathrm{v} / \mathrm{v})$ Nonidet P-40). After removal of the supernatant, immunoprecitated polypeptides were either stored frozen at $-20^{\circ} \mathrm{C}$ or immediately analysed by reducing or non-reducing SDS-PAGE on 4-15\% gradient gels. Gels were fixed for 30 mins in 10\% (v/v) acetic acid, $40 \%(\mathrm{v} /$ v) ethanol and amplified for 20 mins using NAMP100 (GE Healthcare), followed by autoradiography.

\section{List of abbreviations}

Fc: Fragment crystallizable; HRP: horseradish peroxidase; hrs: hours; IgG: Immunoglobulin G; MAb: Monoclonal antibody; mins: minutes; PBS: phosphate-buffered saline; $M_{r}$ : relative molecular mass; SDS-PAGE: sodium dodecylsulfate-polyacrylamide gel electrophoresis; TBS: Tris-buffered saline.

\section{Acknowledgements \\ We would like to acknowledge the generous financial support of the Hotung Foundation, the European COST action for Molecular Pharming (FA0904) and the European Union Pharma-Planta (Framework VI) Integrated Project. We would also like to acknowledge the Wellcome Trust for funding CvD. We are grateful to Thomas Rademacher and Eva Stöger for supplying the transgenic MAb 2G12 seeds for the study. We gratefully acknowledge the reviewers for their helpful contributions and discussions regarding the interpretation of the data presented in this manuscript.}

\section{Authors' contributions}

$\mathrm{VH}$ carried out the experimental work and wrote the manuscript. CVD supervised the project. CVD, JM and PD planned the project and helped to draft the manuscript. MP helped with the pulse chase experiment. All authors read and approved the final manuscript.

Received: 7 April 2011 Accepted: 30 December 2011 Published: 30 December 2011

\section{References}

1. Ma JK, Lehner T, Stabila P, Fux Cl, Hiatt A: Assembly of monoclonal antibodies with $\lg \mathrm{G} 1$ and $\lg A$ heavy chain domains in transgenic tobacco plants. Eur J Immunol 1994, 24(1):131-138.

2. Sharp JM, Doran PM: Characterization of monoclonal antibody fragments produced by plant cells. Biotechnol Bioeng 2001, 73(5):338-346.

3. Villani ME, Morgun B, Brunetti P, Marusic C, Lombardi R, Pisoni I, Bacci C, Desiderio A, Benvenuto E, Donini M: Plant pharming of a full-sized, tumour-targeting antibody using different expression strategies. Plant Biotechnology Journal 2009, 7(1):59-72.

4. Outchkourov NS, Rogelj B, Strukelj B, Jongsma MA: Expression of Sea Anemone Equistatin in Potato. Effects of Plant Proteases on Heterologous Protein Production. Plant Physiol 2003, 133(1):379-390.

5. De Neve M, De Loose M, Jacobs A, Van Houdt H, Kaluza B, Weidle U, Van Montagu M, Depicker A: Assembly of an antibody and its derived antibody fragment in Nicotiana and Arabidopsis. Transgenic Res 1993, 2(4):227-237.

6. Engelen FA, Schouten A, Molthoff JW, Roosien J, Salinas J, Dirkse WG, Schots A, Bakker J, Gommers FJ, Jongsma MA, et al: Coordinate expression of antibody subunit genes yields high levels of functional antibodies in roots of transgenic tobacco. Plant Molecular Biology 1994, 26(6):1701-1710.

7. Stevens LH, Stoopen GM, Elbers IJW, Molthoff JW, Bakker HAC, Lommen A, Bosch D, Jordi W: Effect of Climate Conditions and Plant Developmental Stage on the Stability of Antibodies Expressed in Transgenic Tobacco. Plant Physiol 2000, 124(1):173-182.

8. Faye L, Boulaflous A, Benchabane M, Gomord V, Michaud D: Protein modifications in the plant secretory pathway: current status and practical implications in molecular pharming. Vaccine 2005, 23(15):1770-1778.

9. Schaller $\mathrm{A}$ : A cut above the rest: the regulatory function of plant proteases. Planta 2004, 220(2):183-197.

10. van der Hoorn RAL: Plant Proteases: From Phenotypes to Molecular Mechanisms. Annual Review of Plant Biology 2008, 59(1):191-223.

11. Beyene G, Foyer $\mathrm{CH}$, Kunert KJ: Two new cysteine proteinases with specific expression patterns in mature and senescent tobacco (Nicotiana tabacum L.) leaves. Journal of Experimental Botany 2006, 57(6):1431-1443.

12. De Wilde C, De Rycke R, Beeckman T, De Neve M, Van Montagu M, Engler G, Depicker A: Accumulation pattern of IgG antibodies and Fab fragments in transgenic Arabidopsis thaliana plants. Plant Cell Physiol 1998, 39(6):639-646.

13. Hein MB, Tang $Y$, McLeod DA, Janda KD, Hiatt A: Evaluation of immunoglobulins from plant cells. Biotechnol Prog 1991, 7(5):455-461

14. Benchabane M, Goulet C, Rivard D, Faye LC, Gomord Vr, Michaud D: Preventing unintended proteolysis in plant protein biofactories. Plant biotechnology journal 2008, 6(7):633-648.

15. Rivard D, Anguenot R, Brunelle F, Le VQ, Vezina LP, Trepanier S, Michaud D: An in-built proteinase inhibitor system for the protection of recombinant proteins recovered from transgenic plants. Plant Biotechnology Journal 2006, 4(3):359-368.

16. Benchabane M, Saint-Jore-Dupas C, Bardor M, Faye L, Michaud D, Gomord V: Targeting and post-translational processing of human alpha1antichymotrypsin in BY-2 tobacco cultured cells. Plant Biotechnol J 2009, 7(2):146-160.

17. Michaud D: Gel electrophoresis of proteolytic enzymes. Analytica Chimica Acta 1998, 372(1-2):173-185.

18. Daniell H, Chebolu S, Kumar S, Singleton M, Falconer R: Chloroplastderived vaccine antigens and other therapeutic proteins. Vaccine 2005, 23(15):1779-1783.

19. Vitale A, Pedrazzini E: Recombinant Pharmaceuticals from Plants: The Plant Endomembrane System as Bioreactor. Molecular Interventions 2005 5(4):216-225.

20. Yoshida K, Matsui T, Shinmyo A: The plant vesicular transport engineering for production of useful recombinant proteins. Journal of Molecular Catalysis B: Enzymatic 2004, 28(4-6):167-171.

21. Potenza C, Aleman L, Sengupta-Gopalan C: Targeting transgene expression in research, agricultural, and environmental applications: Promoters used in plant transformation. In Vitro Cellular \& Developmental Biology-Plant 2004, 40(1):1-22.

22. Stoger E, Ma JKC, Fischer R, Christou P: Sowing the seeds of success: pharmaceutical proteins from plants. Current Opinion in Biotechnology 2005, 16(2):167-173.

23. Komarnytsky S, Borisjuk N, Yakoby N, Garvey A, Raskin I: Cosecretion of Protease Inhibitor Stabilizes Antibodies Produced by Plant Roots. Plant Physiol 2006, 141(4):1185-1193.

24. Floss DM, Sack M, Arcalis E, Stadlmann J, Quendler H, Rademacher T, Stoger E, Scheller J, Fischer R, Conrad U: Influence of elastin-like peptide fusions on the quantity and quality of a tobacco-derived human immunodeficiency virus-neutralizing antibody. Plant Biotechnol J 2009, 7(9):899-913. 
25. Frigerio L, Vine ND, Pedrazzini E, Hein MB, Wang F, Ma JK-C, Vitale A: Assembly, Secretion, and Vacuolar Delivery of a Hybrid Immunoglobulin in Plants. Plant Physiol 2000, 123(4):1483-1494.

26. Di Cola A, Frigerio L, Lord JM, Roberts LM, Ceriotti A: Endoplasmic reticulum-associated degradation of ricin $A$ chain has unique and plantspecific features. Plant Physiol 2005, 137(1):287-296.

27. Peterson E, Owens SM, Henry RL: Monoclonal antibody form and function: manufacturing the right antibodies for treating drug abuse. AAPS J 2006, 8(2):E383-390

28. Irons SL, Nuttall J, Floß DM, Frigerio L, Kotzer AM, Hawes C: Fluorescent protein fusions to a human immunodeficiency virus monoclonal antibody reveal its intracellular transport through the plant endomembrane system. Plant Biotechnology Journal 2008, 6(7):649-662.

29. Hassan S, Van Dolleweerd CJ, loakeimidis F, Keshavarz-Moore E, Ma JK-C Considerations for extraction of monoclonal antibodies targeted to different subcellular compartments in transgenic tobacco plants. Plant Biotechnology Journal 2008, 6(7):733-748.

30. Doran PM: Loss of secreted antibody from transgenic plant tissue cultures due to surface adsorption. Journal of Biotechnology 2006, 122(1):39-54.

31. Peterson E, Owens SM, Henry RL: Monoclonal Antibody Form and Function: Manufacturing the Right Antibodies for Treating Drug Abuse. In Drug Addiction. Edited by: Rapaka RS, Sadée W. Springer New York; 2008:87-100.

32. McGarry T, Hough R, Rogers S, Rechsteiner M: Intracellular distribution and degradation of immunoglobulin $G$ and immunoglobulin $G$ fragments injected into HeLa cells. The Journal of Cell Biology 1983, 96(2):338-346.

33. Parham $P$ : On the fragmentation of monoclonal $\lg G 1, \lg G 2 a$, and $\lg G 2 b$ from BALB/c mice. The Journal of Immunology 1983, 131(6):2895-2902.

34. Kim J-K, Tsen M-F, Ghetie V, Sally Ward E: Evidence that the hinge region plays a role in maintaining serum levels of the murine lgG1 molecule. Molecular Immunology 1995, 32(7):467-475.

35. Anelli T, Sitia R: Protein quality control in the early secretory pathway. EMBO J 2008, 27(2):315-327.

36. Roemisch K: Endoplasmic Reticulum Associated Degradation. Annual Review of Cell and Developmental Biology 2005, 21(1):435-456.

37. Pimpl P, Taylor JP, Snowden C, Hillmer S, Robinson DG, Denecke J: GolgiMediated Vacuolar Sorting of the Endoplasmic Reticulum Chaperone BiP May Play an Active Role in Quality Control within the Secretory Pathway. Plant Cell 2006, 18(1):198-211.

38. Pagny S, Denmat-Ouisse LA, Gomord V, Faye L: Fusion with HDEL protects cell wall invertase from early degradation when $\mathrm{N}$-glycosylation is inhibited. Plant Cell Physiol 2003, 44(2):173-182.

39. de Virgilio M, De Marchis F, Bellucci M, Mainieri D, Rossi M, Benvenuto E, Arcioni $S$, Vitale A: The human immunodeficiency virus antigen Nef forms protein bodies in leaves of transgenic tobacco when fused to zeolin. J Exp Bot 2008, 59(10):2815-2829.

40. Hadlington JL, Santoro A, Nuttall J, Denecke J, Ma JK-C, Vitale A, Frigerio L: The C-terminal Extension of a Hybrid Immunoglobulin A/G Heavy Chain Is Responsible for Its Golgi-mediated Sorting to the Vacuole. Mol Biol Cell 2003, 14(6):2592-2602.

41. Nuttall J, Vine N, Hadlington JL, Drake P, Frigerio L, Ma JK-C: ER resident chaperone interactions with recombinant antibodies in transgenic plants. European Journal of Biochemistry 2002, 269(24):6042-6051.

42. Gevaudant F, Duby G, von Stedingk E, Zhao R, Morsomme P, Boutry M: Expression of a Constitutively Activated Plasma Membrane H+-ATPase Alters Plant Development and Increases Salt Tolerance. Plant Physiol 2007, 144(4):1763-1776.

43. Delannoy Ml, Alves G, Vertommen D, Ma J, Boutry M, Navarre C: Identification of peptidases in Nicotiana tabacum leaf intercellular fluid. Proteomics 2008, 8(11):2285-2298.

44. Schiermeyer A, Hartenstein H, Mandal M, Otte B, Wahner V, Schillberg S: A membrane-bound matrix-metalloproteinase from Nicotiana tabacum cv. BY-2 is induced by bacterial pathogens. BMC Plant Biology 2009, 9(1):83.

45. Müntz K, Shutov AD: Legumains and their functions in plants. Trends in Plant Science 2002, 7(8):340-344

46. Pedrazzini E, Giovinazzo G, Bielli A, de Virgilio M, Frigerio L, Pesca M, Faoro F, Bollini R, Ceriotti A, Vitale A: Protein quality control along the route to the plant vacuole. Plant Cell 1997, 9(10):1869-1880. doi:10.1186/1472-6750-11-128

Cite this article as: Hehle et al:: Antibody degradation in tobacco plants: a predominantly apoplastic process. BMC Biotechnology 2011 11:128.

\section{Submit your next manuscript to BioMed Central and take full advantage of:}

- Convenient online submission

- Thorough peer review

- No space constraints or color figure charges

- Immediate publication on acceptance

- Inclusion in PubMed, CAS, Scopus and Google Scholar

- Research which is freely available for redistribution 